\title{
Spatial analysis of care-seeking behavior among malaria patients in China's Malaria Eradication Program: A Geographic Information System Analysis
}

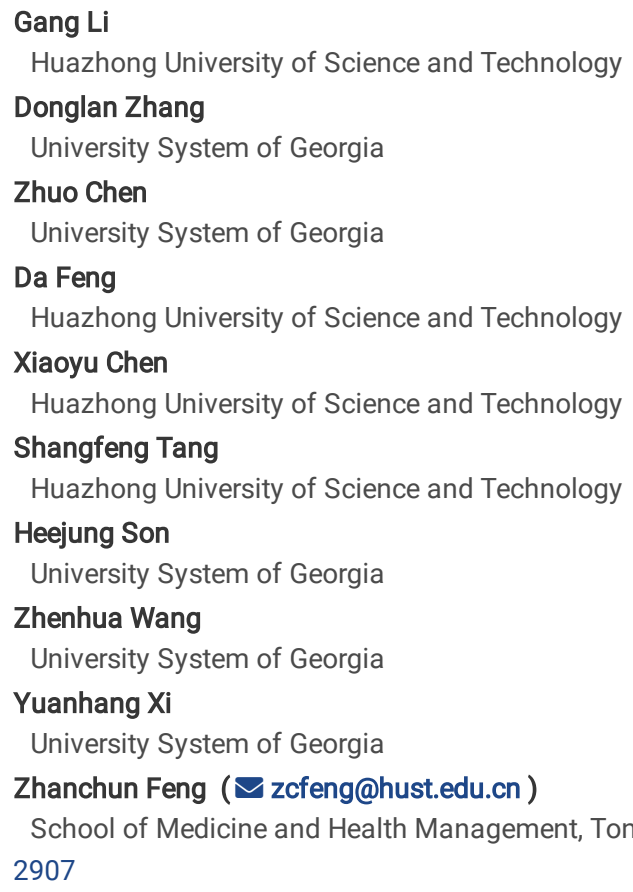

Research

Keywords: Geographic variation, Care-seeking behavior, Geospatial distribution, Medical treatment preference

Posted Date: December 10th, 2019

DOI: https://doi.org/10.21203/rs.2.18503/v1

License: (a) (1) This work is licensed under a Creative Commons Attribution 4.0 International License. Read Full License 


\section{Abstract}

Background: China launched a new round of National Malaria Eradication Program (NMEP) in 2010 that sets the goal to eliminate malaria by 2020, while it has been challenged by the large-scale frequent population migration. To assess the influence of geographic mobility of population on the epidemiology of malaria, we conducted a comprehensive study about the care-seeking behavior among malaria patients.

Methods: The malaria cases were identified within a national database from the National Health Commission of the People's Republic of China. All health institutions and facilities reported malaria patient records during the period from January 2014 to December 2016 . Overall 1633 malaria patients were selected in six provinces located in eastern, central and western China that saw most severe malaria epidemic using stratified sampling. Descriptive statistical analysis was used to investigate the distribution of malaria patients in various medical institutions, and the chi-square test was used to compare the crossregional visit rates of different types of hospitals. Colored maps were drawn to visualize the spatial distribution of hospitals and spatial flow of malaria patients by using the ArcGIS software.

Results: The proportions of malaria patients who sought medical care in general hospitals, township hospitals, and professional public health institutions were $81.7 \%, 14.7 \%$ and $3.6 \%$, respectively. For those who visited hospitals, the percentages who chose provincial, prefecture-level and county-level hospitals for malaria treatment were $17.4 \%, 60.5 \%$ and $22.1 \%$, correspondingly; the proportions of malaria patients who sought medical care in tertiary hospitals, secondary hospitals, and primary hospitals were $59.8 \%, 39.9 \%$ and $0.3 \%$, respectively. Moreover, the proportions of inter-provincial, inter-city and inter-county patients were $3.9 \%, 82.4 \%$ and $80.2 \%$, respectively. In addition, we also found that the percentage of malaria patients who sought treatment in designated hospitals was high.

Conclusion: With the implementation of National Malaria Control Program (NMCP), malaria patients tended to seek medical care in designate tertiary hospitals, and slightly more than half of patients could be treated in health institutions and facilities in prefectural area. In the post-stage of malaria elimination, it is necessary to establish prompt response grassroots hospitals to refer malaria patients to designated malaria treatment hospitals.

\section{Background}

Malaria is one of the most prevalent vector-borne diseases in the world, which can easily cause a damaging impacts on society and the economy[1-3]. According to the latest available data, an estimated of 219 million malaria cases occurred worldwide, and 435,000 deaths associated with malaria were reported in 2017[4, 5]. As a category B notifiable infectious disease, malaria had been prevalent in China[6]. After Chinese government put a great deal of efforts into the malaria epidemic, the morbidity and mortality of malaria had reached its lowest level in the history of the late 20th Century. However, after 2000, a resurgence of malaria occurred in China, and peaked in 2006 with approximately 64,178 malaria cases reported[7-9]. China immediately launched the National Malaria Control Program (NMCP) (2006-2015) with the partnership of the Global Fund project[10, 11]. With the effective implementation of measures such as multi-sectorial cooperation and communication strategy, the incidence of locally-acquired malaria has declined sharply during the period 2006-2010 in China [12-14].

After 2010, the prevalence of malaria was different from that in the past. Almost all cases were imported cases due to the increasing number of immigrant workers and foreign travelers[15], and the vast majority of cases were falciparum malaria. Once the treatment is delayed, the patient is prone to develop severe malaria with a higher mortality $[16,17]$. At the same time, the epidemic area of malaria in China had expanded from 24 traditional malaria-endemic provinces to 31 provinces across the country. In response to the changing epidemiology of malaria, China had also released the Action Plan of China Malaria Elimination (APCME) (2010-2020) as a component of their efforts to eradicate malaria and a response to the Millennium Development Goals issued by the United Nations $[3,7,18]$. The APCME also sets several goals, one is that above $95 \%$ of clinicians in relevant departments of provincial, prefecture, county-level and township medical institutions have received malaria diagnosis and treatment knowledge training[19, 20].

In the period of accelerated malaria eradication, the characteristics of care-seeking behavior among malaria patients, whether the medical resources within the scope in each prefectural area meet the needs of diagnosis and treatment for malaria patients have not been conclusive[21]. This study intends to explore the care-seeking behavior in malaria patients during the process of malaria elimination, in order to provide evidence for the prevention and treatment of imported malaria in the context of frequent population migration.

\section{Methods}

\section{Study design and data source}

We analyzed case-based surveillance data reported from health care providers and collected by the National Health Commission of the People's Republic of China during January 2014 - December 2016. In order to analyze the spatial flow of patients who sought medical care in general hospitals, we used the stratified sampling method to select 6 provinces with the most severe malaria epidemic in Eastern, Central and Western China, which were, Zhejiang and Jiangsu provinces from Eastern China; Henan and Anhui provinces from Central China; Yunnan and Sichuan provinces from Western China. We then selected 2 provincial hospitals, 5 prefecture-level hospitals, 10 county-level hospitals from each province. Among a total of 102 hospitals, the medical records of all malaria cases within the hospital were collected. Overall a total of 1,633 malaria cases were investigated.

\section{Variables and pre-processing}

Hospital address information and Chinese administrative vector map were obtained from the National Medical Institution Inquiry System and the National Geospatial Information Center, respectively[22, 23]. The patients address information was derived from the medical records. Then we geocoded the address using Baidu Map Application Programming Interface (API), and defined as (a) inter-county proportion of malaria patients = Number of inter-county malaria 
patients/total number of malaria patients; (b) inter-city proportion of malaria patients = number of inter-city malaria patients/ total number of malaria patients; (c) inter-provincial proportion of malaria patients = number of inter-provincial malaria patients/total number of malaria patients. In this study, provincial hospitals were those ran by provincial administrative departments, prefecture-level hospitals were those ran by the prefectural government, and county (district) hospitals were those ran by county (district) governments. The institutions reporting malaria cases can be classified as general hospitals, grassroots medical institutions, and the Centers for Disease Control and Prevention (CDCs). Grassroots medical institutions referred to community healthcare center/clinic, township hospital and village clinic.

\section{Data analysis and mapping}

Data were double entered into the Microsoft Excel 2016 (Microsoft Corporation, USA) and then a descriptive analysis was conducted. Colored maps were created to visualize the spatial distribution of hospitals for treating malaria and spatial flow of malaria patients using the ArcGIS software version 10.7 (ESRI, USA)[24], and the World Geodetic System 1984 (WGS84) was used as the reference coordinate system[25]. The graduated symbol renderer on the Layer Properties in ArcGIS was used to present the distribution of the hospital, that is, hospitals were shown with unique colors, and the number of malaria cases treated in each hospital was shown using a graduated symbol. The "XY To Line" analyst tool of ArcToolbox in ArcGIS was used to illustrate the patient spatial flow.

\section{Results}

\section{Distribution of malaria patients in health institutions}

A total of 3,686 malaria cases were reported in 616 medical and public health institutions in the surveillance system during the period from 2014 to 2016 , which included outpatient and inpatient cases. Overall, provinces in Western China reported the largest number of malarias, followed by the Eastern and Central regions. A total of 467 hospitals in six provinces reported 3,011 cases, accounting for $81.7 \%$ of the total reported cases; and 117 township hospitals reported 542 cases of malaria, accounting for $14.7 \%$ of the total reported cases, and 32 Centers for Disease Control and Prevention (CDCs) reported 133 malaria patients, accounting for $3.6 \%$ of the total reported cases, as shown in Table 1.

Table 1

Distribution of malaria patients in health institutions

\begin{tabular}{|llllllll|}
\hline Type of medical institution & $\begin{array}{l}\text { Total } \\
\mathbf{N = 3 6 8 6}\end{array}$ & \multicolumn{2}{l}{ Eastern China } & \multicolumn{2}{ll}{ Central China } & \multicolumn{2}{l|}{ Western China } \\
\cline { 3 - 7 } & & $\begin{array}{l}\text { Zhejiang } \\
\mathbf{N = 5 1 7}\end{array}$ & $\begin{array}{l}\text { Jiangsu } \\
\mathbf{N = 7 0 9}\end{array}$ & $\begin{array}{l}\text { Anhui } \\
\mathbf{N}=\mathbf{3 4 1}\end{array}$ & $\begin{array}{l}\text { Henan } \\
\mathbf{N}=\mathbf{4 3 2}\end{array}$ & $\begin{array}{l}\text { Sichuan } \\
\mathbf{N}=\mathbf{6 2 2}\end{array}$ & $\begin{array}{l}\text { Yunnan } \\
\mathbf{N}=\mathbf{1 0 6 5}\end{array}$ \\
\hline General Hospital & $3011(81.7 \%)$ & $458(88.6 \%)$ & $667(94.1 \%)$ & $315(92.4 \%)$ & $421(97.5 \%)$ & $581(93.4 \%)$ & $569(53.4 \%)$ \\
\hline Township hospital & $542(14.7 \%)$ & $13(2.5 \%)$ & $24(3.4 \%)$ & $22(6.5 \%)$ & $2(0.46 \%)$ & $20(3.2 \%)$ & $461(43.3 \%)$ \\
\hline CDCs & $133(3.6 \%)$ & $46(8.9 \%)$ & $18(2.5 \%)$ & $4(1.2 \%)$ & $9(2.08 \%)$ & $21(3.4 \%)$ & $35(3.3 \%)$ \\
\hline
\end{tabular}

The proportions of malaria patients in Henan, Jiangsu, Sichuan, and Anhui provinces who seek medical care in hospitals exceeded $90 \%$, which were $97.5 \%$, $94.1 \%, 93.4 \%$, and $92.4 \%$, respectively. While the proportion of patients in Yunnan province who sought medical care in hospitals was less than $60 \%$.

The proportion of malaria patients in Yunnan who sought medical care in township hospitals was the highest, reaching 43.3\%, while the proportion of patients in most provinces who sought medical care in township hospitals was less than $5 \%$. The proportion of patients in most provinces who sought medical care in Centers for Disease Control and Prevention (CDCs) was less than $3 \%$.

\section{Distribution of malaria patients in hospitals}

Since China's hospital system was administrated by governments at the provincial, prefecture-level and county-level, hospitals can be classified into provincial hospitals, prefecture-level hospitals and county-level hospitals. There were $17.4 \%(n=524)$ patients who sought medical care in provincial hospitals, as shown in Table $2,60.5 \%(n=1822)$ patients who sought medical care in prefecture-level hospitals, and $22.1 \%(n=665)$ patients who sought medical care in countylevel hospitals. China also has a three-tiered hospital classification system, hospitals can also be classified into tertiary hospitals, secondary hospitals and primary hospitals according to their service delivery capability. There were $59.8 \%(n=1801)$ patients who sought health care in tertiary hospitals, $39.9 \%(n=$ 1202) patients who sought health care in secondary hospitals, and $0.3 \%(n=8)$ patients who sought health care in primary hospitals. 
Table 2

Distribution of malaria patients seeking health care in hospitals

\begin{tabular}{|c|c|c|c|c|c|c|c|}
\hline \multirow[t]{3}{*}{ Hospital type } & \multirow{3}{*}{$\begin{array}{l}\text { Total } \\
\mathrm{N}=3011\end{array}$} & \multicolumn{2}{|c|}{ Eastern China } & \multicolumn{2}{|c|}{ Central China } & \multicolumn{2}{|c|}{ Western China } \\
\hline & & Zhejiang & Jiangsu & Anhui & Henan & Sichuan & Yunnan \\
\hline & & $N=458$ & $N=667$ & $N=315$ & $N=421$ & $N=581$ & $N=569$ \\
\hline \multicolumn{8}{|l|}{ Hospital tier } \\
\hline Provincial & $524(17.4 \%)$ & $65(14.2 \%)$ & $22(3.3 \%)$ & 142(45.1\%) & $245(58.2 \%)$ & $43(7.4 \%)$ & $7(1.2 \%)$ \\
\hline Prefecture-level & $1822(60.5 \%)$ & $279(60.9 \%)$ & $484(72.6 \%)$ & $87(27.6 \%)$ & 162(38.5\%) & $396(68.2 \%)$ & $414(72.8 \%)$ \\
\hline County & $665(22.1 \%)$ & 114(24.9\%) & $161(24.1 \%)$ & $86(27.3 \%)$ & $14(3.2 \%)$ & $142(24.4 \%)$ & $148(26.0 \%)$ \\
\hline \multicolumn{8}{|l|}{ Hospital level } \\
\hline Tertiary & $1801(59.8 \%)$ & $335(73.1 \%)$ & $402(60.3 \%)$ & $218(69.2 \%)$ & $356(84.6 \%)$ & $329(56.6 \%)$ & $161(28.3 \%)$ \\
\hline Secondary & 1202(39.9\%) & $123(26.9 \%)$ & $258(38.7 \%)$ & $97(30.8 \%)$ & $65(15.4 \%)$ & $252(43.4 \%)$ & $407(71.5 \%)$ \\
\hline Primary & $8(0.3 \%)$ & $0(0.0 \%)$ & $7(1.0 \%)$ & $0(0.0 \%)$ & $0(0.0 \%)$ & $0(0.0 \%)$ & $1(0.2 \%)$ \\
\hline
\end{tabular}

The proportions of malaria patients who sought care in tertiary hospitals in Zhejiang, Jiangsu, Anhui, Henan, Sichuan and Yunnan Provinces was 73.1\%, $60.3 \%, 69.2 \%, 84.6 \%, 56.6 \%$ and $28.3 \%$, respectively; the proportions of malaria patients who sought medical care in secondary hospitals in Zhejiang, Jiangsu, Anhui, Henan, Sichuan and Yunnan Provinces was 26.9\%, 38.7\%, 30.8\%, 15.4\%, 43.4\% and 71.5\%, respectively; except for Jiangsu and Yunnan Provinces, no malaria patients sought medical care in primary hospitals in other aforementioned provinces.

\section{The characteristics of the top 10 hospitals treating most malaria patients}

The number of hospitals reporting malaria cases in Zhejiang, Jiangsu, Anhui, Henan, Sichuan, and Yunnan provinces were 103, 92, 56, 49, 91, and 76, respectively. The percentages of top 10 hospitals treating most malaria patients in Zhejiang, Jiangsu, Anhui, Henan, Sichuan, and Yunnan provinces were $51.2 \%, 62.7 \%, 78.4 \%, 84.1 \%, 59.9 \%$, and $76.1 \%$, respectively. The proportions of cases in hospitals with the largest number of cases in Zhejiang, Jiangsu, Anhui, Henan, Sichuan, and Yunnan provinces accounted for $10.5 \%, 10.8 \%, 23.8 \%, 52.8 \%, 27.5 \%$, and 17.8\%, respectively, as shown in Table 3 .

Table 3

The characteristics of the top 10 hospitals treating most malaria cases

\begin{tabular}{|lllllll|}
\hline Province & NA $^{\mathbf{a}}$ & PA $^{\mathbf{b}}$ & NB $^{\mathbf{c}}$ & NAME $^{\mathbf{d}}$ & NC $^{\mathbf{e}}$ & PC $^{\mathbf{f}}$ \\
\hline Zhejiang & 103 & $51.2 \%$ & 4 & Yiwu Central Hospital & 47 & $10.5 \%$ \\
\hline Jiangsu & 92 & $62.7 \%$ & 6 & Taizhou People's Hospital & 72 & $10.8 \%$ \\
\hline Anhui & 56 & $78.4 \%$ & 4 & Anhui Provincial Hospital & 75 & $23.8 \%$ \\
\hline Henan & 49 & $84.1 \%$ & 4 & Henan Infectious Disease Hospital & 196 & $52.8 \%$ \\
\hline Sichuan & 91 & $59.9 \%$ & 5 & Chengdu Public Health Clinical Medical Center & 160 & $27.5 \%$ \\
\hline Yunnan & 76 & $76.1 \%$ & 8 & Ruili Rende Hospital & 101 & $17.8 \%$ \\
\hline
\end{tabular}

\section{Spatial distribution of hospitals for treating malaria}

Figure 1 shows the hospital spatial distribution in our dataset from 2014 to 2016, which included 2,961 cases in 467 hospitals. The bigger dots represent large number of cases and the smaller dots represent small number of cases treated in hospitals. We can see the hospitals in each provincial capital city treated most malaria cases. Hospitals in most cities in Zhejiang, Jiangsu, and Sichuan provinces treated a number of malaria cases. Hospitals in fewer cities in Anhui, Henan, and Yunnan provinces treated most malaria cases. For example, hospitals located in Hefei city (Anhui), Zhengzhou and Luoyang city (Henan), Kunming and Baoshan city (Yunnan) treated the majority of cases in their provinces.

\section{Spatial flow analysis of malaria patients who sought medical care in hospitals}

Of the 1633 patients surveyed, $3.9 \%(n=64)$ were inter-provincial patients. This article did not compare the proportion of inter-provincial patients in different provinces due to the number was small, which did not allow us to do a chi-square test.

The proportion of inter-city patients in the survey sample was $36.6 \%(n=597)$, as shown in Table 4. The proportions of inter-city patients in Zhejiang, Jiangsu, Anhui, Henan, Sichuan, and Yunnan provinces were $35.4 \%, 9.1 \%, 19.5 \%, 46.8 \%, 39.0 \%$, and $65.8 \%$, respectively. The proportions of inter-city patients in secondary and tertiary hospitals were $41.7 \%(n=156)$ and $35.0 \%(n=441)$, respectively, which varied substantially from province to province. There was a significant difference in the proportion of inter-city patients between the second and tertiary hospitals in Zhejiang, Henan, Sichuan, and Yunnan provinces. The proportion of inter-city patients in tertiary hospitals was significantly higher than that in secondary hospitals in Zhejiang and Henan provinces, while the situation in Sichuan and Yunnan provinces in Western China was just the opposite. The proportions of inter-city patients in provincial hospitals, prefecturelevel hospitals and county-level hospitals were $60.3 \%(n=232), 23.1 \%(n=194)$, and $42.0 \%(n=171)$, respectively. There was a significant difference in the 
proportion of patients among different levels of hospitals. In most provinces, the proportion of inter-city patients who sought medical care in provincial hospitals was higher than that in prefecture-level hospitals and county-level hospitals except for Anhui province.

Table 4

Characteristics of inter-city spatial mobility in malaria patients

\begin{tabular}{|c|c|c|c|c|c|c|c|c|c|c|c|c|}
\hline \multirow[t]{2}{*}{ Province } & \multirow{2}{*}{$\begin{array}{l}\text { Flow } \\
\text { type }\end{array}$} & \multirow[t]{2}{*}{$\mathbf{N}$} & \multirow[t]{2}{*}{$\%$} & \multicolumn{2}{|l|}{ Hospital tier } & \multirow[t]{2}{*}{$x^{2}$} & \multirow{2}{*}{$\begin{array}{l}P \\
\text { value }\end{array}$} & \multicolumn{2}{|l|}{ Hospital level } & $x^{2}$ & \multicolumn{2}{|c|}{$P$ value } \\
\hline & & & & Tertiary & Secondary & & & Provincial & Prefecture & County & & \\
\hline Zhejiang & $\begin{array}{l}\text { No } \\
\text { Inter- } \\
\text { city }\end{array}$ & 82 & $64.60 \%$ & $10(100.0 \%)$ & $72(61.5 \%)$ & 5.957 & 0.015 & $26(50.0 \%)$ & 48(72.7\%) & $8(88.9 \%)$ & 9.071 & 0.011 \\
\hline$N=127$ & $\begin{array}{l}\text { Inter- } \\
\text { city }\end{array}$ & 45 & $35.40 \%$ & $0(0.0 \%)$ & $45(38.5 \%)$ & & & $26(50.0 \%)$ & $18(27.3 \%)$ & $1(11.1 \%)$ & & \\
\hline Jiangsu & $\begin{array}{l}\text { No } \\
\text { Inter- } \\
\text { city }\end{array}$ & 379 & $90.90 \%$ & 84(93.3\%) & $295(90.2 \%)$ & 0.829 & 0.363 & $5(50.0 \%)$ & 228(89.1\%) & $146(96.7 \%)$ & 27.350 & 0.000 \\
\hline$N=417$ & $\begin{array}{l}\text { Inter- } \\
\text { city }\end{array}$ & 38 & $9.10 \%$ & $6(6.7 \%)$ & $32(9.8 \%)$ & & & $5(50.0 \%)$ & $28(10.9 \%)$ & $5(3.3 \%)$ & & \\
\hline Anhui & $\begin{array}{l}\text { No } \\
\text { Inter- } \\
\text { city }\end{array}$ & 33 & $80.50 \%$ & $22(84.6 \%)$ & 11(73.3\%) & 0.771 & 0.380 & $7(70.0 \%)$ & $7(58.3 \%)$ & 19(100.0\%) & 9.057 & 0.011 \\
\hline$N=41$ & $\begin{array}{l}\text { Inter- } \\
\text { city }\end{array}$ & 8 & $19.50 \%$ & $4(15.4 \%)$ & $4(26.7 \%)$ & & & $3(30.0 \%)$ & $5(41.7 \%)$ & $0(0.0 \%)$ & & \\
\hline Henan & $\begin{array}{l}\text { No } \\
\text { Inter- } \\
\text { city }\end{array}$ & 224 & $53.20 \%$ & $65(98.5 \%)$ & $159(44.8 \%)$ & 64.450 & 0.000 & $87(31.5 \%)$ & 131(95.6\%) & $6(75.0 \%)$ & 152.643 & 0.000 \\
\hline$N=421$ & $\begin{array}{l}\text { Inter- } \\
\text { city }\end{array}$ & 197 & $46.80 \%$ & $1(1.5 \%)$ & $196(55.2 \%)$ & & & $189(68.5 \%)$ & $6(4.4 \%)$ & $2(25.0 \%)$ & & \\
\hline Sichuan & $\begin{array}{l}\text { No } \\
\text { Inter- } \\
\text { city }\end{array}$ & 236 & $61.00 \%$ & $24(39.3 \%)$ & $212(65.0 \%)$ & 14.249 & 0.000 & $25(80.6 \%)$ & 158(61.7\%) & $53(53.0 \%)$ & 7.773 & 0.021 \\
\hline$N=387$ & $\begin{array}{l}\text { Inter- } \\
\text { city }\end{array}$ & 151 & $39.00 \%$ & $37(60.7 \%)$ & $114(35.0 \%)$ & & & $6(19.4 \%)$ & $98(38.3 \%)$ & $47(47.0 \%)$ & & \\
\hline Yunnan & $\begin{array}{l}\text { No } \\
\text { Inter- } \\
\text { city }\end{array}$ & 82 & $34.20 \%$ & 13(10.7\%) & $69(58.0 \%)$ & 59.523 & 0.000 & $3(50.0 \%)$ & $75(65.8 \%)$ & $4(3.3 \%)$ & 102.070 & 0.000 \\
\hline$N=240$ & $\begin{array}{l}\text { Inter- } \\
\text { city }\end{array}$ & 158 & $65.80 \%$ & 108(89.3\%) & $50(42.0 \%)$ & & & $3(50.0 \%)$ & $39(34.2 \%)$ & 116(96.7\%) & & \\
\hline Total & $\begin{array}{l}\text { No } \\
\text { Inter- } \\
\text { city }\end{array}$ & 1036 & $63.40 \%$ & $218(58.3 \%)$ & $818(65.0 \%)$ & 5.553 & 0.018 & 153(39.7\%) & 647(76.9\%) & $236(58 . \%)$ & 164.467 & 0.000 \\
\hline$N=1633$ & $\begin{array}{l}\text { Inter- } \\
\text { city }\end{array}$ & 597 & $36.60 \%$ & $156(41.7 \%)$ & $441(35.0 \%)$ & & & $232(60.3 \%)$ & 194(23.1\%) & $171(42.0 \%)$ & & \\
\hline
\end{tabular}

The proportion of inter-county patients in the survey sample was 81.8\%(1336), as shown in Table 5. The proportions of inter-county patients in Zhejiang, Jiangsu, Anhui, Henan, Sichuan, and Yunnan was 96.9\% ( $n=123), 52.3 \%(n=218), 53.7 \%(n=22), 91.0 \%(n=383), 96.6 \%(n=374)$, and 90.0\% $(n=216)$, respectively. There was a significant difference in the proportion of inter-city patients between the second and tertiary hospitals in Jiangsu, Anhui, Henan, and Yunnan provinces. The proportion of inter-county patients in tertiary hospitals was significantly higher than that in secondary hospitals. The proportions of inter-county patients in provincial hospitals, prefecture-level hospitals and county-level hospitals was $94.0 \%, 88.0 \%$, and $56.8 \%$, respectively. There was a significant difference in the proportions of patients among different levels of hospitals in Jiangsu, Anhui, Henan, Sichuan and Yunnan provinces. 
Table 5

Characteristics of inter-county spatial mobility in malaria patients

\begin{tabular}{|c|c|c|c|c|c|c|c|c|c|c|c|c|}
\hline \multirow[t]{2}{*}{ Province } & \multirow{2}{*}{$\begin{array}{l}\text { Flow } \\
\text { type }\end{array}$} & \multirow[t]{2}{*}{$\mathbf{N}$} & \multirow[t]{2}{*}{$\%$} & \multicolumn{2}{|l|}{ Hospital tier } & \multirow[t]{2}{*}{$x^{2}$} & \multirow{2}{*}{$\begin{array}{l}P \\
\text { value }\end{array}$} & \multicolumn{3}{|c|}{ Hospital level } & \multirow[t]{2}{*}{$x^{2}$} & \multirow{2}{*}{$\begin{array}{l}P \\
\text { value }\end{array}$} \\
\hline & & & & Tertiary & Secondary & & & Provincial & Prefecture & County & & \\
\hline Zhejiang & $\begin{array}{l}\text { No } \\
\text { Inter- } \\
\text { county }\end{array}$ & 4 & $3.10 \%$ & $1(10.0 \%)$ & $3(2.6 \%)$ & 1.67 & 0.196 & $1(1.9 \%)$ & $0(0.0 \%)$ & $3(33.3 \%)$ & 29.283 & 0.511 \\
\hline$N=127$ & $\begin{array}{l}\text { Inter- } \\
\text { county }\end{array}$ & 123 & $96.90 \%$ & $9(90.0 \%)$ & 114(97.4\%) & & & $51(98.1 \%)$ & $66(96.0 \%)$ & 6(66.7\%) & & \\
\hline Jiangsu & $\begin{array}{l}\text { No } \\
\text { Inter- } \\
\text { county }\end{array}$ & 199 & $47.70 \%$ & $83(92.2 \%)$ & 116(35.5\%) & 91.101 & 0.000 & $0(0.0 \%)$ & $53(20.7 \%)$ & $146(96.7 \%)$ & 229.163 & 0.001 \\
\hline$N=417$ & $\begin{array}{l}\text { Inter- } \\
\text { county }\end{array}$ & 218 & $52.30 \%$ & $7(7.8 \%)$ & $211(64.5 \%)$ & & & $10(100.0 \%)$ & 203(79.3\%) & $5(3.3 \%)$ & & \\
\hline Anhui & $\begin{array}{l}\text { No } \\
\text { Inter- } \\
\text { county }\end{array}$ & 19 & $46.30 \%$ & $17(65.4 \%)$ & $2(13.3 \%)$ & 10.364 & 0.001 & $0(0.0 \%)$ & $0(0.0 \%)$ & 19(100.0\%) & 41.000 & 0.001 \\
\hline$N=41$ & $\begin{array}{l}\text { Inter- } \\
\text { county }\end{array}$ & 22 & $53.70 \%$ & $9(34.6 \%)$ & $13(86.7 \%)$ & & & $10(100.0 \%)$ & $12(100.0 \%)$ & $0(0.0 \%)$ & & \\
\hline Henan & $\begin{array}{l}\text { No } \\
\text { Inter- } \\
\text { county }\end{array}$ & 38 & $9.00 \%$ & 21(31.8\%) & $17(4.8 \%)$ & 49.516 & 0.000 & $15(5.4 \%)$ & $20(14.6 \%)$ & $3(37.5 \%)$ & 17.415 & 0.001 \\
\hline$N=421$ & $\begin{array}{l}\text { Inter- } \\
\text { county }\end{array}$ & 383 & $91.00 \%$ & $45(68.2 \%)$ & $338(95.2 \%)$ & & & $261(94.6 \%)$ & $117(85.4 \%)$ & $5(62.5 \%)$ & & \\
\hline Sichuan & $\begin{array}{l}\text { No } \\
\text { Inter- } \\
\text { county }\end{array}$ & 13 & $3.40 \%$ & $0(0.0 \%)$ & $13(4.0 \%)$ & 2.517 & 0.113 & $6(19.4 \%)$ & $7(2.7 \%)$ & $0(0.0 \%)$ & 28.217 & 0.001 \\
\hline$N=387$ & $\begin{array}{l}\text { Inter- } \\
\text { county }\end{array}$ & 374 & $96.60 \%$ & $61(100.0 \%)$ & $313(96.0 \%)$ & & & $25(80.6 \%)$ & 249(97.3\%) & $100(100.0 \%)$ & & \\
\hline Yunnan & $\begin{array}{l}\text { No } \\
\text { Inter- } \\
\text { county }\end{array}$ & 24 & $10.00 \%$ & $4(3.3 \%)$ & $20(16.8 \%)$ & 12.151 & 0.000 & $1(16.7 \%)$ & 19(16.7\%) & $4(3.3 \%)$ & 11.852 & 0.00 \\
\hline$N=240$ & $\begin{array}{l}\text { Inter- } \\
\text { county }\end{array}$ & 216 & $90.00 \%$ & 117(96.7\%) & $99(83.2 \%)$ & & & $5(83.3 \%)$ & 95(83.3\%) & 116(96.7\%) & & \\
\hline Total & $\begin{array}{l}\text { No } \\
\text { Inter- } \\
\text { county }\end{array}$ & 297 & $18.20 \%$ & 126(33.7\%) & 171(13.6\%) & 78.351 & 0.000 & $23(6.0 \%)$ & $99(11.8 \%)$ & $175(43.0 \%)$ & 230.230 & 0.001 \\
\hline$N=1633$ & $\begin{array}{l}\text { Inter- } \\
\text { county }\end{array}$ & 1336 & $81.80 \%$ & $248(66.3 \%)$ & 1088(86.4\%) & & & $362(94.0 \%)$ & 742(88.2\%) & $226(57.0 \%)$ & & \\
\hline
\end{tabular}

\section{Discussion}

The six sampled provinces we selected were areas where there were more malaria cases compared to other provinces in recent years[10, 26]. Nearly all malaria cases were imported into China during 2014-2016[27], following a large number of people traveling overseas in those provinces[28].

Most malaria patients sought medical care in general hospitals, followed by township hospitals and professional public health agencies. The majority of imported malaria was falciparum malaria. Patients with falciparum malaria were often in poor health and needed timely medical first aid[29], so hospitals were playing an increasingly important role in the reporting, diagnosis and treatment of malaria cases[30].

We analyzed patients who sought medical care in hospitals and found that the proportions of patients in tertiary hospitals and prefecture-level hospitals were the highest. This was because China's tertiary hospitals and prefecture-level hospitals had a full range of inspection facilities to provide higher quality medical services.

Based on the map of the distribution of hospitals and patients flow (as shown in Figs. 2 and 3), we can see there was a large number of patients who sought care in hospitals located in capital cities. Within the scope of each prefectural area, most patients tended to seek care in hospitals located in cities. The overall proportions of inter-county and inter-city patients were $81.8 \%$ and $36.6 \%$, respectively. This may be due to the progress of malaria elimination in China, countylevel hospitals had begun to weaken their understanding of malaria, and doctors had insufficient skills or experiences in malaria diagnosis and treatment[31]. This may easily lead to delays in some imported malaria cases of non-malaria endemic areas.

Although the proportion of inter-county patients was high, the overall proportion of inter-city patients in the sampled provinces was relatively low, this meant that a certain amount of malaria cases could be treated in hospitals located in each prefecture. However, the proportions of inter-city patients varied substantially from province to province. Compared with other provinces, the malaria cases distribution in hospitals in Jiangsu province was unique. The 
proportion of inter-city patients in Jiangsu was much lower than that in other provinces. This meant that most malaria cases could be treated in hospitals located in each prefecture, which was a good medical treatment pattern. This good situation was inseparable from the actual situation in Jiangsu. The number of imported malaria cases in Jiangsu had been ranked third nationwide, and the number of falciparum malaria cases ranked first in the country[32, 33]. The Jiangsu government put great importance to the elimination of malaria, and Jiangsu took the lead in putting forward the "1-3-7" approach: case reporting within 1 day, case investigation within 3 days, and case investigation and disposal of the epidemic within 7 days[34]. Meanwhile various forms of technical training were carried out annually, almost all staff in various health agencies mastered the malaria rapid diagnostic tests (RDTs)[35-37].

Compared with Jiangsu, the proportion of inter-city patients in Yunnan and Henan was much higher. Located in Central China, Henan had a flat terrain and a well-established transportation network[38]. Malaria patients could easily access hospitals in Capital Cities. In our study, we also found that the Henan Infectious Disease Hospital, a designated hospital for malaria treatment, accepted more than $50 \%$ of malaria patients. This shows that malaria patients may be diagnosed in grassroots medical institutions and then were referred to the provincial infectious disease hospitals. Compared with Henan, Yunnan was a mountainous terrain, despite the inconvenience of transportation, the proportion of inter-city was still high[39, 40]. Moreover, the institution that treated malaria most was a private hospital that had not been certified as a secondary hospital by the local government, nor was it a designated hospital for malaria treatment. To a certain extent, this indicated that the grassroots medical institutions were insufficient to fully cope with malaria[41, 42], which was likely to cause delays of malaria patients.

Another interesting finding in our study was that the top 10 hospitals treating malaria most accepted nearly $70 \%$ of cases on average, and designated hospitals for malaria treatment accounted for a large proportion. This may have a lot to do with the implementation of the National Malaria Elimination Program (NMEP). According to the requirements of the NMEP, the health bureau of each province should set up designated hospitals for malaria treatment and strengthen the publicity of the hospitals and knowledge of malaria prevention. To some extent, this also affected the choice of medical institutions for malaria patients, resulting in a certain concentration of medical institutions in the geographical space. This also showed that after the implementation of the NMEP, patients can get effective referrals, which can greatly reduce the delay for patients with severe malaria.

\section{Limitations}

This study has at least three limitations. First, the hospitals sampled in each province were the result of taking into account the local economy, hospital location and number of cases. We did not include hospitals with a small sample size. Second, the actual collection of malaria cases was lower than expected due to the reluctance of sampled hospital staff or the loss of cases due to the renewal of the electronic case system. For example, we only collected 41 cases in Anhui Province, this will lead to instability in the analysis of Anhui. Third, when we analyzed the patient's flow, we did not pay attention to the intermediate process of the patient's visit, and some patients may be treated in the grassroots hospitals and were later referred to the higher level hospitals.

\section{Conclusions}

The results of this study illustrated spatial distribution of malaria patients seeking medical care during the malaria elimination stage. With the implementation of the NMEP, malaria patients tended to seek medical care in malaria designated tertiary hospitals, and medical services provided by the hospital within each prefectural area can largely met the care needs of patients. A higher proportion of inter-county patients reminded that the diagnosis and treatment capacity of grassroots hospitals may be insufficient, which may lead to delays in malaria treatment, resulting in life-threatening and huge economic burden. In the elimination stage of malaria, the scope and extent of the malaria epidemic has fallen to the level of historically low, local governments should formulate corresponding prevention and control strategies according to their own regional realities. It was necessary to continue to strengthen the monitoring of fever symptoms in people entering the epidemic areas[43], and consolidate the ability of grassroots hospital staff to carry out RDTs and microscopic examination, and establish rapid response referrals for malaria patients between grassroots hospitals and malaria designated treatment hospitals.

\section{Abbreviations}

WHO, World Health Organization; NMEP, National Malaria Elimination Program; Rapid Diagnostic Tests (RDTs); APCME, Action Plan of China Malaria Elimination; CDCs, Centers for Disease Control and Prevention

\section{Declarations}

\section{Ethics approval and consent to participate}

Ethical approval was obtained from the Ethics Committee of Tongji Medical College, Huazhong University of Science \& Technology (IORG No: IORG0003571). Permission was taken from National Health Commission of People's Republic China and from the manager of each hospital.

\section{Consent for publication}

Not applicable.

\section{Availability of data and materials}

The datasets used in the current study are available from the corresponding author and will also be presented as an attachment in the article.

\section{Funding}


This study was supported by the National Health Commission of PRC Project "Malaria Elimination Assessment and Malaria Policy Analysis" and National Natural Science Foundation of China (grant no. 71673098).

\section{Competing interests}

The authors declare that they have no competing interests. The funders had no role in study design, data collection and analysis, decision to publish, or preparation of the manuscript.

Authors' contributions

GL, ZCF and DLZ conceived and planed the study, SFT, GL and CYC collected the data, GL, ZC and XYC conducted the data analysis, GL and DLZ wrote the paper. ZC, DF, HS, ZHW and YHX commented and revised drafts of the manuscript. All authors read and approved the final manuscript.

\section{Acknowledgements}

We would like to acknowledge Disease Prevention and Control Bureau, National Health Commission of the People's Republic of China for their strong support of this study. The data collection also was conducted with the help of Center for Diseases Control and Prevention in Zhejiang, Jiangsu, Anhui, Henan, Yunnan and Sichuan. The authors would like to thank all the respondents for data collection and the staff in CDCs and health administrative department for their assistance.

\section{References}

1. Ghani AC: Can improving access to care help to eliminate malaria? Lancet 2018, 391:1870-1871.

2. Plewes K, Leopold SJ, Kingston HWF, Dondorp AM: Malaria: What's New in the Management of Malaria? Infect Dis Clin North Am 2019, 33:39-60.

3. Chen I, Cooney R, Feachem RGA, Lal A, Mpanju-Shumbusho W: The Lancet Commission on malaria eradication. Lancet 2018, 391:1556-1558.

4. WHO: World malaria report 2018. 2018.

5. Lover AA, Coker RJ: The challenges of malaria elimination. The Lancet 2013, 382:1699-1700.

6. Zhou ZJ: The malaria situation in the People's Republic of China. Bull World Health Organ 1981, 59:931-936.

7. Wang RB, Zhang QF, Zheng B, Xia ZG, Zhou SS, Tang LH, Gao Q, Wang LY, Wang RR: Transition from control to elimination: impact of the 10-year global fund project on malaria control and elimination in China. Adv Parasito/ 2014, 86:289-318.

8. Huang Q, Hu L, Liao QB, Xia J, Wang QR, Peng HJ: Spatiotemporal Analysis of the Malaria Epidemic in Mainland China, 2004-2014. Am J Trop Med Hyg 2017, 97:504-513.

9. Newby G, Larson E, Shretta R, Bennett A, Phillips AA: Chinese action towards global malaria eradication Reply. Lancet 2016, 388:959-960.

10. Zheng Q, Vanderslott S, Jiang B, Xu LL, Liu CS, Huo LL, Duan LP, Wu NB, Li SZ, Xia ZG, et al: Research gaps for three main tropical diseases in the People's Republic of China. Infect Dis Poverty 2013, 2:15.

11. Moonen B, Cohen JM, Snow RW, Slutsker L, Drakeley C, Smith DL, Abeyasinghe RR, Rodriguez MH, Maharaj R, Tanner M, Targett G: Operational strategies to achieve and maintain malaria elimination. The Lancet 2010, 376:1592-1603.

12. Hu T, Liu YB, Zhang SS, Xia ZG, Zhou SS, Yan J, Cao J, Feng ZC: Shrinking the malaria map in China: measuring the progress of the National Malaria Elimination Programme. Infect Dis Poverty 2016, 5:52.

13. Zhou SS, Wang Y, Xia ZG: [Malaria situation in the People's Republic Of China in 2009]. Zhongguo Ji Sheng Chong Xue Yu Ji Sheng Chong Bing Za Zhi 2011, 29:1-3

14. Zhou SS, Wang Y, Li Y: [Malaria situation in the People's Republic of China in 2010]. Zhongguo Ji Sheng Chong Xue Yu Ji Sheng Chong Bing Za Zhi 2011, 29:401-403.

15. Lai S, Sun J, Ruktanonchai NW, Zhou S, Yu J, Routledge I, Wang L, Zheng Y, Tatem AJ, Li Z: Changing epidemiology and challenges of malaria in China towards elimination. Malar J 2019, 18:107.

16. Wangdi K, Gatton ML, Kelly GC, Banwell C, Dev V, Clements ACA: Malaria elimination in India and regional implications. The Lancet Infectious Diseases 2016, 16:e214-e224.

17. Romay-Barja M, Cano J, Ncogo P, Nseng G, Santana-Morales MA, Valladares B, Riloha M, Benito A: Determinants of delay in malaria care-seeking behaviour for children 15 years and under in Bata district, Equatorial Guinea. Malar J 2016, 15:187.

18. Action Plan of China Malaria Elimination (2010-2020) [http://www.nhc.gov.cn/jkj/s5873/201005/f84f1c4b0f32420990d23b65a88e2d87.shtml]

19. Lu GY, Liu YB, Beiersmann C, Feng Y, Cao J, Muller O: Operational challenges to the 1-3-7 surveillance strategy for malaria elimination in China: a qualitative study. Lancet 2016, 388:15-15.

20. Wang R, Tang S, Yang J, Shao T, Shao P, Liu C, Feng D, Fu H, Chen X, Hu T, Feng Z: Improving local health workers' knowledge of malaria in the elimination phase-determinants and strategies: a cross-sectional study in rural China. Malar J 2017, 16:210.

21. Fu H, Hu T, Wang JY, Feng D, Fang HQ, Wang ML, Tang SF, Yuan F, Feng ZC: A bibliometric analysis of malaria research in China during $2004-2014$. Malaria Journal 2015, 14.

22. National medical institution inquiry system [http://61.49.18.120:9090/unit/index]

23. center NGI: National Geospatial Information system. 2018. 
24. Newby G, Bennett A, Larson E, Cotter C, Shretta R, Phillips AA, Feachem RGA: The path to eradication: a progress report on the malaria-eliminating countries. Lancet 2016, 387:1775-1784.

25. Noor AM, Kinyoki DK, Mundia CW, Kabaria CW, Mutua JW, Alegana VA, Fall IS, Snow RW: The changing risk of Plasmodium falciparum malaria infection in Africa: 2000-10: a spatial and temporal analysis of transmission intensity. Lancet 2014, 383:1739-1747.

26. Lin HL, Lu L, Tian LW, Zhou SS, Wu HX, Bi Y, Ho SC, Liu QY: Spatial and temporal distribution of falciparum malaria in China. Malaria Journal2009, 8:9.

27. Li ZJ, Zhang Q, Zheng CJ, Zhou S, Sun JL, Zhang ZK, Geng QB, Zhang HL, Wang LP, Lai SJ, et al: Epidemiologic features of overseas imported malaria in the People's Republic of China. Malaria Journal 2016, 15.

28. Yang GJ, Tanner M, Utzinger J, Malone JB, Bergquist R, Chan EYY, Gao Q, Zhou XN: Malaria surveillance-response strategies in different transmission zones of the People's Republic of China: preparing for climate change. Malaria Journal 2012, 11:9.

29. Lynch M, Korenromp E, Eisele T, Newby H, Steketee R, Kachur SP, Nahlen B, Yoon S, MacArthur J, Newman R, Cibulskis R: New global estimates of malaria deaths. Lancet 2012, 380:559-559.

30. Feachem RGA, Phillips AA, Hwang J, Cotter C, Wielgosz B, Greenwood BM, Sabot O, Rodriguez MH, Abeyasinghe RR, Ghebreyesus TA, Snow RW: Shrinking the malaria map: progress and prospects. The Lancet 2010, 376:1566-1578.

31. Lubell Y: Cost-effective use of prereferral treatment for severe malaria. Lancet 2010, 376:1880-1881.

32. Cao YY, Wang WM, Liu YB, Cotter C, Zhou HY, Zhu GD, Tang JX, Tang F, Lu F, Xu S, et al: The increasing importance of Plasmodium ovale and Plasmodium malariae in a malaria elimination setting: an observational study of imported cases in Jiangsu Province, China, 2011-2014. Malaria Journal 2016, 15.

33. Liu YB, Hsiang MS, Zhou HY, Wang WM, Cao YY, Gosling RD, Cao J, Gao Q: Malaria in overseas labourers retuming to China: an analysis of imported malaria in Jiangsu Province, 2001-2011. Malaria Journal 2014, 13.

34. Cao J, Sturrock HJ, Cotter C, Zhou S, Zhou H, Liu Y, Tang L, Gosling RD, Feachem RG, Gao Q: Communicating and monitoring surveillance and response activities for malaria elimination: China's "1-3-7" strategy. PLoS Med 2014, 11:e1001642.

35. Yuan-Yuan C, Hua-Yun Z, Guo-Ding Z, Wei-Ming W, Jia-Jie J, Wen-Ji Q, Jia-Yan H, Jun C: [Challenges for maintaining achievements of malaria elimination in Jiangsu Province, China]. Zhongguo Xue Xi Chong Bing Fang Zhi Za Zhi 2018, 30:460-464.

36. Sabot O, Cohen JM, Hsiang MS, Kahn JG, Basu S, Tang L, Zheng B, Gao Q, Zou L, Tatarsky A, et al: Costs and financial feasibility of malaria elimination. The Lancet 2010, 376:1604-1615.

37. Hsiang MS, Hwang J, Tao AR, Liu YB, Bennett A, Shanks GD, Cao J, Kachur SP, Feachem RGA, Gosling RD, Gao Q: Mass drug administration for the control and elimination of Plasmodium vivax malaria: an ecological study from Jiangsu province, China. Malaria Journal $2013,12$.

38. Liu Y, Zhang HW, Zhou RM, Yang CY, Qian D, Zhao YL, Xu BL: First imported relapse case of Plasmodium vivax malaria and analysis of its origin by CSP sequencing in Henan Province, China. Malaria Journal 2014, 13.

39. Clements ACA, Barnett AG, Cheng ZW, Snow RW, Zhou HN: Space-time variation of malaria incidence in Yunnan province, China. Malaria Journal 2009, 8:12.

40. Zhou SS, Huang F, Wang JJ, Zhang SS, Su YP, Tang LH: Geographical, meteorological and vectorial factors related to malaria reemergence in Huang-Huai River of central China. Malaria Journal 2010, 9:9.

41. Tang S, Feng D, Wang R, Ghose B, Hu T, Ji L, Wu T, Fu H, Huang Y, Feng Z: Economic burden of malaria inpatients during National Malaria Elimination Programme: estimation of hospitalization cost and its inter-province variation. Malar J 2017, 16:291.

42. Tang S, Ji L, Hu T, Wang R, Fu H, Shao T, Liu C, Shao P, He Z, Li G, Feng Z: Public awareness of malaria in the middle stage of national malaria elimination programme. A cross-sectional survey in rural areas of malaria-endemic counties, China. Malar J 2016, 15:373.

43. Song YZ, Ge Y, Wang JF, Ren ZP, Liao YL, Peng JH: Spatial distribution estimation of malaria in northern China and its scenarios in 2020, 2030, 2040 and 2050. Malaria Journal 2016, 15.

\section{Figures}



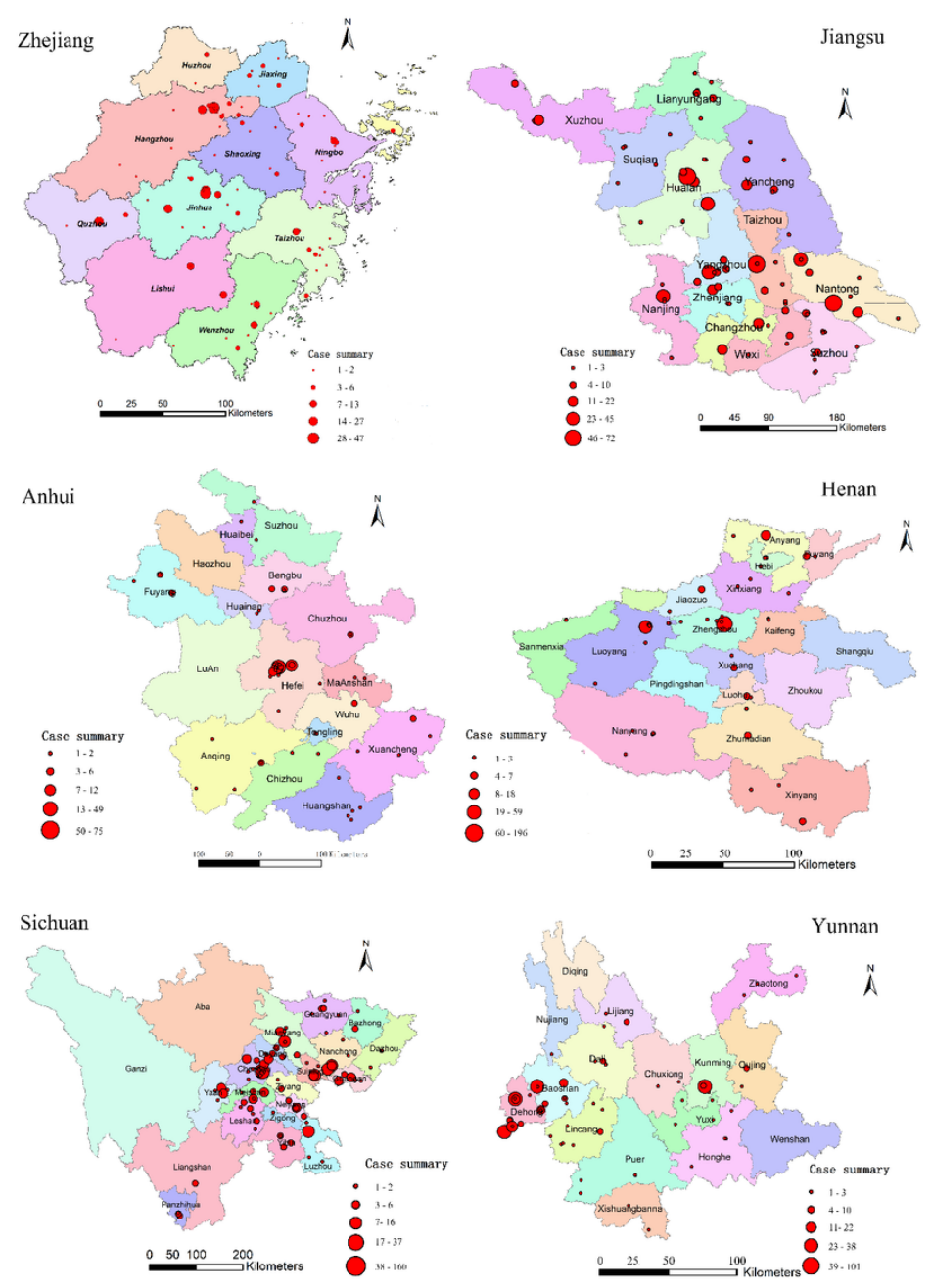

\section{Figure 1}

Spatial distribution of hospitals for malaria treatment. Note: The designations employed and the presentation of the material on this map do not imply the expression of any opinion whatsoever on the part of Research Square concerning the legal status of any country, territory, city or area or of its authorities, or concerning the delimitation of its frontiers or boundaries. This map has been provided by the authors. 


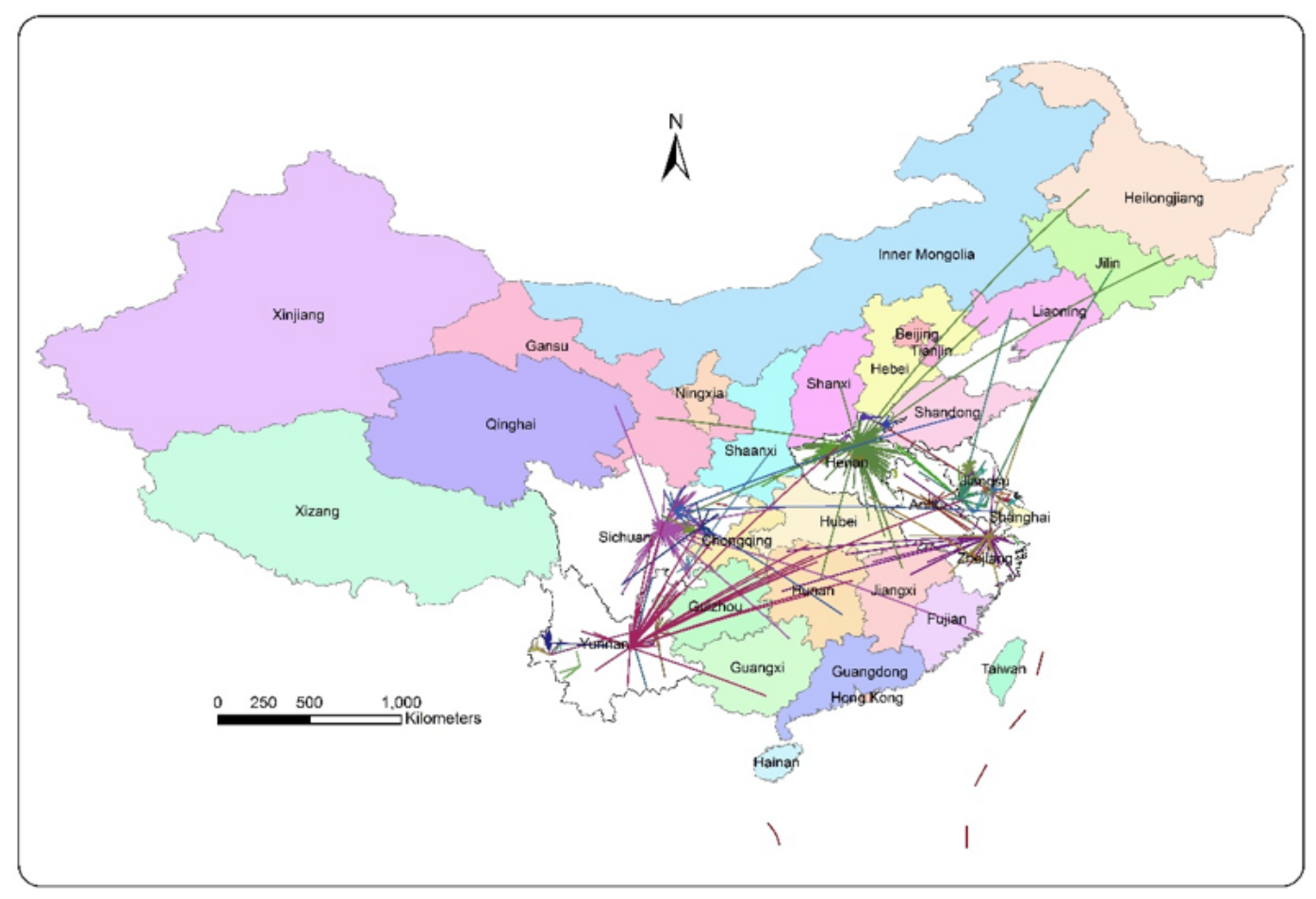

Note: The point of aggregation is the starting point.

Figure 2

Overview of the spatial flow of malaria patients who sought medical care in hospitals. Note: The designations employed and the presentation of the material on this map do not imply the expression of any opinion whatsoever on the part of Research Square concerning the legal status of any country, territory, city or area or of its authorities, or concerning the delimitation of its frontiers or boundaries. This map has been provided by the authors. 


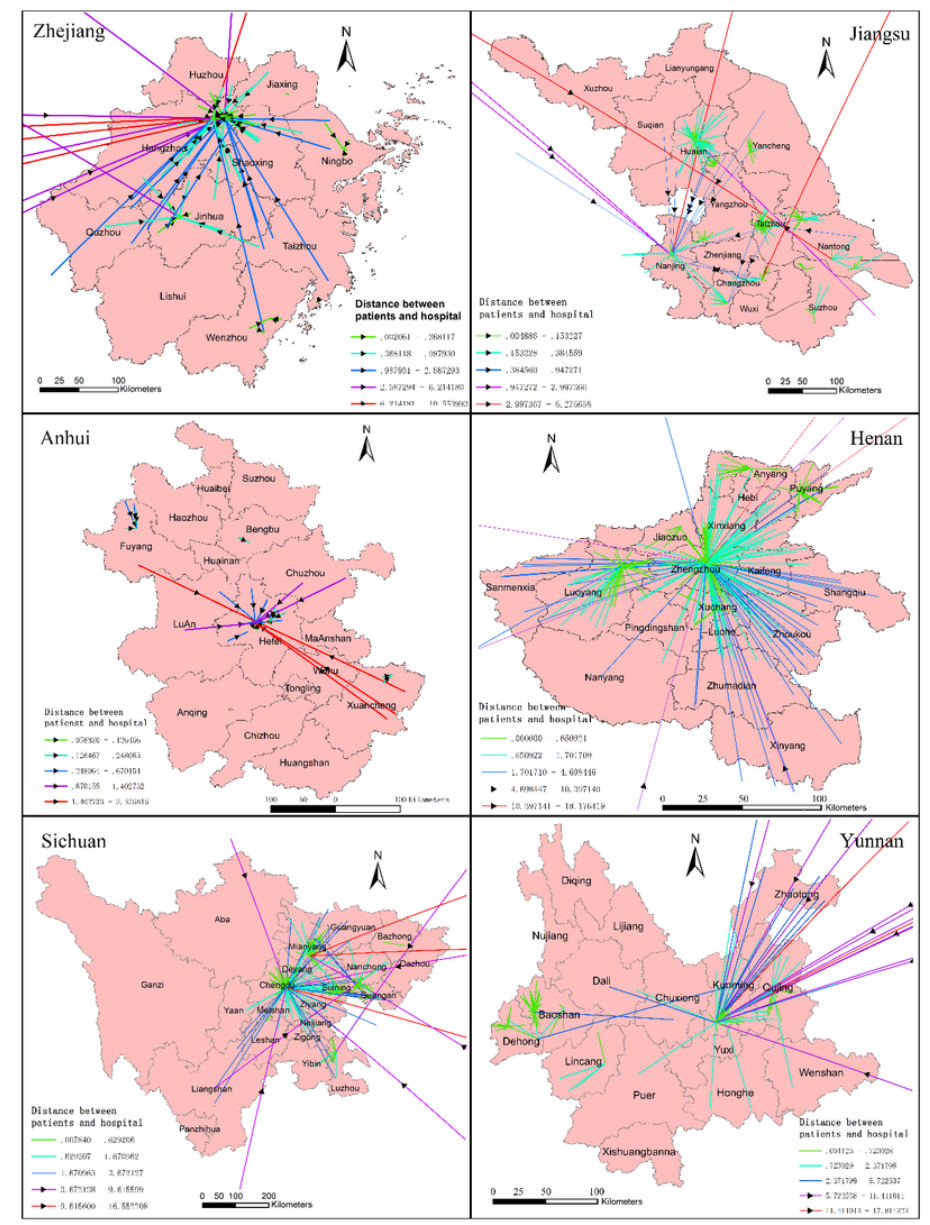

\section{Figure 3}

Spatial flow of malaria patients who sought medical care in hospitals. Note: The designations employed and the presentation of the material on this map do not imply the expression of any opinion whatsoever on the part of Research Square concerning the legal status of any country, territory, city or area or of its authorities, or concerning the delimitation of its frontiers or boundaries. This map has been provided by the authors. 